\title{
Herir la lengua. Por una política de la singularidad -Derrida, lector de Celan-
}

\section{To wound the language. Towards a politics of singularity ${ }^{1}$-Derrida reads Celan-}

\author{
Miriam Jerade \\ Universidad Autónoma Metropolitana - Unidad Cuajimalpa. México. \\ miriamjerade@gmail.com
}

\section{Resumen}

El presente ensayo intenta hacer un análisis de las lecturas que Derrida hace de la poesía de Paul Celan a partir de la noción de idioma como la posibilidad del singular de marcar la lengua. Ahondaremos en la pulsión del idioma como Derrida la expone en El monolingüismo del otro haciendo una referencia a la firma que hace Celan en la lengua alemana, luego analizaremos la relación entre el idioma y el duelo como testimonio de las fechas en Schibboleth y Carneros y, por último, revisaremos las dos sesiones que Derrida dedica a la lectura de El Meridiano de Celan, en el seminario La bestia y el soberano, en los que Derrida ahondará en la contra-palabra [Gegenwort], como una contra-violencia al discurso soberano.

Palabras clave: Derrida, Celan, Schibboleth, El Meridiano.

\begin{abstract}
My article examines Jacques Derrida's readings of Paul Celan's poetry. I take the concept of "idiom" as my initial analytical tool. I understand this concept as the singular's ability to mark language up. In the first part, I put the concept of the "idiom's drive" (pulsion de l'idiome) under closer examination. I refer to Derrida's use of this concept in his Monolinguism of the Other and his reading about Celan's signature in the German language. I subsequently examine the relationship between idiom and mourning as witnessed by the dates found in Schibboleth and Rams. I finally examine the two sessions Derrida devoted to reading Celan's Meridian in the seminar The Beast and the Sovereign, when Derrida deepened his grasp of "counterword" (Gegen-Wort) as conveying a counter-violence against sovereign discourse.
\end{abstract}

Keywords: Derrida, Celan, Schibboleth, The Meridian.

1 El título de este artículo en su traducción al inglés "towards a politics of singularity" hace ecos del trabajo que Samuel Weber ha desarrollado en los últimos años sobre las dimensiones de una política y una poética de la singularidad en la obra de Jacques Derrida, que hasta donde tengo entendido serán el tema de su próximo libro.

Este artículo se hizo gracias a una beca para el fortalecimiento del postgrado del Conacyt y a la hospitalidad del departamento de Humanidades de la UAM-Cuajimalpa. Quisiera expresar mi gratitud a Mariana di Cio, Andreas Ilg y a Jesús de Prado, quienes leyeron y comentaron una versión previa de este trabajo. 
La poesía de Celan se hace presente (por espectral) en la obra de Jacques Derrida a partir de 1984, en la conferencia que el filósofo impartió en Seattle publicada bajo el título de Schibboleth, seguido por Carneros: entre dos infinitos, el poema de 2003, en memoria de Gadamer. En 2004 publicó "Poétique et politique du témoignage" en Le Cahier de l'Herne y finalmente en 2008 en las actas del seminario impartido entre 2001-2002, de publicación póstuma La Bestia y el Soberano, Derrida consagró dos sesiones a la lectura de El Meridiano, la alocución que Celan pronunció con motivo de la recepción del premio Georg Büchner en 1960.

Si bien Derrida y Celan eran colegas en la École Normale Supérieur desde 1964, sólo se conocieron en 1968 a través de Peter Szondi, dos años antes de que Celan se quitase la vida. Pasarán varios años antes de que Derrida escriba sobre la poesía de Celan. Quizás una de las razones sea que en aquella época no se había aún traducido la poesía de Celan al francés ${ }^{2}$, pues si bien Derrida la lee en alemán, en sus textos siempre cita más de una traducción y en más de una lengua ${ }^{3}$ para mostrar una paradoja que atraviesa la deconstrucción: por un lado la exigencia de traducir, por el otro, la resistencia del idioma a la traducción o su intraducibilidad. En una entrevista realizada por Evelyne Grossman para la Revue Europe en 2001, Derrida sostiene que el idioma es lo que resiste a la traducción:

El idioma es lo que resiste a la traducción, pues lo que aparentemente está atado a la singularidad del cuerpo significante de la lengua o del cuerpo a secas pero que, a causa de esa singularidad, se sustrae a toda posesión, a toda reivindicación de pertenencia. La dificultad política es: ¿cómo estar a favor de la más grande idiomaticidad -lo que hay que hacer, creo- defendiéndose en todo contra la ideología nacionalista? ¿Cómo defender la diferencia lingüística sin ceder al patriotismo, en todo caso a cierto tipo de patriotismo, y al nacionalismo? Tal es el desafío político de este tiempo ("La lengua no pertenece").

En este contexto, es importante subrayar la diferencia que hay entre "idiome" en francés e "idioma", ya que en español, idioma es casi un sinónimo de lengua, mientras que en francés tiene una connotación de particularidad, siguiendo su etimología griega: la particularidad del estilo y, según su etimología latina: una lengua particular ${ }^{4}$. El idiome es un concepto clave en el pensamiento derridiano. Por "idioma” se entenderá lo que es propio, una manera singular de firmar en la lengua. Derrida hace en sus últimas obras referencia a la poesía de Celan cuando habla del idioma, si bien, ya en

2 André du Bouchet y publica extractos de De umbral en umbral de 1955 hasta 1978. Jean-Pierre Léfèbvre publica una traducción al francés de "Fuga de muerte" en 1986.

3 Como bien lo subraya Marc Crépon en su texto "Traduire, témoigner, survivre", Derrida propone hasta cinco versiones: el texto original, las traducciones al francés de André du Bouchet y de Jean-Pierre Lefèvre, traducción al inglés de la Joachim Neugroschen y finalmente, aunque sin asumir su propia traducción, termina con una posibilidad propia: "On pourrait aussi traduire", "On pourrait encore traduire". Marc Crépon, "Traduire, témoigner, survivre”, Rue Descartes 52,2 (2006). 27-38.

4 Fuente: Centre Nationale de Ressources Textuelles et Lexicales. www.cnrtl.fr/etymologie/idiome 
sus obras tempranas había mencionado el idioma, por ejemplo en "Freud y la escena de la escritura" publicado en La escritura y la diferencia, donde Derrida relaciona el idioma con la escritura psíquica que "no se deja leer a partir de ningún código" y agrega: "[...] en sus operaciones, su léxico y su sintaxis se mantiene irreductible un residuo puramente idiomático, que tiene que llevar todo el peso de la interpretación, en la comunicación entre los inconscientes. El soñador inventa su propia gramática"(288). Derrida reconoce aquí algo particular a la gramática del soñador que es irreductible e intraducible a un lenguaje universal o que a pesar de ser traducido a una narración coherente en el lenguaje de la vigilia, guarda un residuo puramente idiomático. Pero no solamente el lenguaje del inconsciente es idiomático; también la filosofía lo es: en su estilo, en sus particulares giros que de alguna manera ejercen, según la tradición, una ruptura con el lenguaje común para ofrecerlo al pensamiento. Sin embargo, Derrida hace referencia al idioma sobre todo para referirse a una firma en la lengua, una manera singular de usar el lenguaje a propósito de Rousseau, de Ponge o de Artaud (Bennington). Pero Derrida no sólo se refiere al lenguaje escrito, en La verdad en pintura afirma que le interesa el idioma en pintura y habla de la firma de Cézanne como un evento.

En Poétique et politique du témoignage, Derrida relaciona la singularidad de una marca idiomática, de una experiencia poética con el testimonio: “tout témoignage responsable engage une expérience poétique de la langue” $(521)^{5}$, pero a su vez, el idioma sería la invención poética en la lengua de la cual sólo ella puede dar testimonio. Es sobre todo en este último sentido que Derrida se compromete a una lectura singular de la poesía de Celan. Esto puede atribuirse en mi parecer a tres factores: 1) Derrida muestra que Celan nos confronta a una cierta experiencia de la lengua, a partir de una contra-firma en la lengua alemana; 2) La lectura singular de la poética de Celan se basa en una paradoja en torno a la intraducibilidad del idioma, que pasa por una experiencia de la traducción, y que Derrida resume de la siguiente manera: “[...] en su alemán poético hay una lengua de partida y una lengua de llegada y cada poema es una suerte de nuevo idioma en el cual hace pasar la herencia de la lengua alemana"; ("La lengua no pertenece") 3) El idioma ofrece la posibilidad de darle un futuro a la lengua y de ofrecerla al otro. Pero abrir la lengua al futuro es también reconocer, para Derrida, la idiomaticidad poética como memoria de las fechas y rememoración de los muertos, es decir, testimonios de lo único, de lo irremplazable.

En el presente artículo analizaremos, a partir de esos tres ejes, las lecturas que Derrida hace de Celan en relación al idioma. Primeramente haremos un recorrido por El monolingüismo del otro, texto de 1996 que cerrará con una evocación del idioma de Celan. Si bien dicha obra no es expresamente sobre Celan, en ella Derrida ahonda sobre ese deseo de invención del idioma a partir de una reflexión sobre el hecho de hablar una lengua, de la cual depende nuestra singularidad, no sólo en su condición

5 Todo testimonio responsable compromete una experiencia poética de la lengua. Traducción de la autora. 
existencial sino también en su dimensión política, ya que toda construcción identitaria se mantiene a partir de un fantasma de la pertenencia y exige una apropiación de la lengua y de sus normas. En un segundo momento analizaremos la relación entre el idioma y el duelo como testimonio de las fechas a partir de las lecturas que Derrida hace de la poesía de Celan en Schibboleth y Carneros: entre dos infinitos, el poema. Por último, analizaremos las dos sesiones del seminario que Derrida dedica a la lectura de El Meridiano de Celan, en los que Derrida ahondará en la contra-palabra [Gegenwort], como una contra-violencia al discurso soberano.

El idioma es eco de uno de los nódulos de la deconstrucción: la crítica de la naturalización de la lengua, particularmente de la lengua materna, pues la única manera de desapropiar la lengua, de no ceder al patriotismo, según Derrida, es firmar la lengua en singular. Lo paradójico del idioma es, por una parte, que su singularidad no establece un idioma privado sino que el idioma se dirige al otro; por otra parte, que su singularidad -el hecho de firmar en la lengua que podría resolverse en la mayor apropiación- la defiende de toda reivindicación de pertenencia, lo que hace que el idioma en Derrida tenga una dimensión política.

En una entrevista con Evelyne Grossman, Derrida relaciona el idioma con el evento que es un tema constante en las últimas obras de Derrida sobre la hospitalidad, el perdón o el testimonio:

Creo que Celan ensayó una marca, una firma singular que fue una contra-firma de la lengua alemana y al mismo tiempo algo que adviene a la lengua alemana -que adviene en los dos sentidos de este término: que se aproxima a la lengua alemana, que acude a ella, sin apropiársela, sin someterse a ella, sin entregarse a ella, pero al mismo tiempo haciendo que la escritura poética advenga, es decir sea un acontecimiento que marque la lengua. [...] lo que me parece es que toca a la lengua alemana a la vez con respecto al genio idiomático de la lengua alemana, pero también en el sentido en que la hace moverse, en que le deja una suerte de cicatriz, de marca, de herida ("La lengua no pertenece").

El evento es lo que adviene de manera singular, no se inscribe dentro de una continuidad o un horizonte de espera; irrumpe. Pero a su vez, eso que irrumpe de manera singular en un presente, hace una marca del pasado -Derrida habla de cicatriz- y abre a la lengua a un futuro, hace que algo advenga en la propia lengua, es decir, con respecto al genio idiomático que hace a la singularidad de cada lengua pero también, respecto a la agencia -y también a la responsabilidad- que cada uno tiene sobre la lengua.

\section{La pulsión del idioma}

La relación de Celan con la lengua alemana fue muy peculiar, así como lo fue la de Derrida con la lengua francesa si bien son dos casos históricos y políticos muy parti- 
culares y disímiles entre sí. El alemán no era la lengua hablada en la Czernowitz natal de Celan; John Felstiner, en la biografía que consagró al poeta, cita el testimonio de uno de los compañeros de colegio: "No poseíamos una lengua natural [...] hablar buen alemán era algo que tenías que lograr. Podías hacerlo, pero no se daba por sí mismo" (31). El alemán en el que escribe Celan, si bien le viene de su madre, no tiene el estatuto de lengua materna sino de una lengua conquistada. En cambio, la historia de Derrida y su relación con la lengua francesa estuvo marcada por una realidad colonial que exigía la apropiación de una lengua que era siempre la lengua de la metrópoli, de "ellos". Pero además, Derrida pasa por una situación muy particular, traumática, cifrada sobre todo en una excepción, y que describe en El monolingüismo del otro o la prótesis de origen, pues entre 1940 y 1943, bajo el mandato de Vichy ${ }^{6}$, la ciudadanía que los judíos de Argelia habían adquirido en 1870 por el decreto Crémieux ${ }^{7}$, les fue retirada. Esto develó no sólo el desarraigo de la comunidad judía, incapaz de reconocerse en una lengua nacional o comunitaria, sino también lo que según Derrida constituye la relación de todo sujeto con la lengua que se construye a partir de "un proceso no natural de construcciones político-fantasmáticas" (El monolingüismo 30), pero que siempre se oblitera en la idea de la lengua materna como propiedad natural. A través de esta experiencia de la pérdida, Derrida describe la condición del monolingüe con la frase: "Sí, no tengo más que una lengua; ahora bien, no es la mía" (5). A partir de dicha condición, Derrida desarrollará la cuestión del idioma en tanto que pulsión, lo que se relaciona con el subtítulo de la obra: "La prótesis del origen", pues la deconstrucción es siempre la demostración de una contaminación en el origen y una desmitificación de la idea de un origen puro o simple, perdido en algún momento de la historia, comenzando por la idea de una lengua originaria o pura. El idioma es justamente una suerte de contaminación.

La experiencia del monolingüe reside en la tensión entre la exigencia de apropiarse una lengua, de hablarla y escribirla correctamente y la imposibilidad de hacerlo. La infancia de Celan estuvo impregnada por el rumano, el francés, el ruso y el yiddish; sin embargo, escribió su obra en alemán, logró escribir en alemán con propiedad, sin ser ésta una lengua materna y quizás dos autores de lengua alemana como Celan y Kafka tuvieron en común vivir esta tensión de la imposible apropiación de manera aún más aguda, una tensión que pasa por el cuerpo -el cuerpo del que escribe y el cuerpo de la lengua- pues como lo enuncia Derrida, aprender una lengua es soportar un cuerpo a cuerpo con ella:

6 Derrida deja muy claro en el texto que esto fue obra de una decisión administrativa francesa, pues Argelia nunca fue ocupada por los alemanes: "Argelia nunca estuvo ocupada. Con esto quiero decir que si alguna vez lo estuvo, no fue ciertamente por el Ocupante alemán. El retiro de la ciudadanía francesa a los judíos de Argelia, con todo lo que siguió, fue obra exclusiva de los franceses" (El monolingüismo del otro 30).

7 El decreto Crémieux fue promulgado en 1870 por Isaac Adolphe Crémieux, distinguido jurista judeo-francés que logró que Napoleón III les concediera la nacionalidad francesa a alrededor de 37.000 judíos de Argelia, retirándoles el estatuto civil del que disponían hasta entonces. En 1940, el general Pétain promulga la ley sobre el estatuto de los judíos y abroga el decreto Crémieux. 
[...] lo que sugiero es que no se apropia una lengua sino para soportar un cuerpo a cuerpo con ella. Lo que trato de pensar es un idioma (y el idioma quiere decir lo propio justamente, lo que es propio) y una firma en el idioma de la lengua que hace al mismo tiempo la experiencia de la inapropiabilidad de la lengua ("La lengua no pertenece").

En Schibboleth, Derrida escribe a propósito del idioma: "Firmado: Celan en algún lugar de la lengua alemana, que fue su única propiedad” (20). Hay una paradoja entre lo propio y lo inapropiable que revela una de las realidades de hablar una lengua: la lengua nos viene del otro, sus reglas y su ortografía se nos imponen cual una ley. Sin embargo, la exigencia de apropiación que pesa sobre todo hablante de una lengua, la de "hablarla correctamente", de "escribirla correctamente", es decir, de someterse a su ley, se confronta con el idioma que, en ese insertarle un cuerpo extraño para marcar la lengua, la desapropia de su pretendida homogeneidad.

Tanto Celan como Kafka estuvieron además expuestos al yiddish, un idioma que enfrenta a la lengua alemana a la experiencia de lo intraducible; la jerga, como le llamaba Kafka, arrima al hablante del alemán a una experiencia de lo ominoso (unheimlich), es decir, una familiaridad extraña. Así lo expone Kafka en el "Discurso sobre la lengua yiddish", pronunciado para inaugurar una representación de obras de teatro judío ${ }^{8}$ de Jizchak Löwy en 1912:

Por fortuna, todo el que conozca el idioma alemán, comprenderá la jerga. Pues, cuando se lo contempla a distancia, la comprensibilidad exterior de éste está formada por la lengua alemana; es esta una ventaja sobre las demás lenguas del mundo. Como es equitativo, también tiene una desventaja con respecto a ellas. Consiste en que no se puede traducir la jerga al idioma alemán. Las conexiones entre ambos son tan tenues y significativas que no pueden sino desgarrarse cuando se vuelca la jerga al alemán, es decir, ya no se vierte jerga, sino algo insustancial. Traduciéndolo al francés, por ejemplo, la jerga puede transmitirse a los franceses; con la traducción al alemán, se le aniquila (Kafka 421-6)9.

Kafka expone aquí que la condición idiomática del yiddish o de la jerga, como le llama. El yiddish sería ese "otro" de la lengua alemana que a su vez, es intraducible al alemán porque pierde en cierta medida el significado de su agencia sobre la lengua alemana. Por un lado, el yiddish depende de la hospitalidad del alemán, ya que no pertenece a ninguna nación sino a la condición de errar del pueblo judío; por otro lado, como bien lo expone Marc Crépon en Langues sans demeure, el yiddish es intraducible

8 En 1940, Paul Celan conoce a Ruth Lackner, joven actriz del Teatro Estatal Yiddish y a través de ella a otras personas relacionadas con el teatro yiddish.

9 Revisamos también la traducción al francés de Marthe Robert, "Discours sur la langue yiddish". Préparatifs de noce à la campagne (1957). 371-74. Versión en castellano: http://severitorres.org/ampa/joomla/images/Biblioteca/K/ kafka/discurso\%20sobre\%20la\%20lengua\%20yiddish.pdf. 
al alemán puesto que es cuestión de escuchar desde el alemán su diferencia. Así, el yiddish tiene una relación particular con el alemán, una relación yo diría ominosa, entre la proximidad y la alteridad. Celan ejerce sobre el alemán algo parecido a lo que hace la jerga: desvía a la lengua de su propia inteligibilidad.

Por ejemplo: en el poema "Nah, im Aortenbogen"10 de 1967 incluido en Soles filamentos [Fadensonnen], Celan inserta la alteridad del yiddish que es intraducible al alemán. Este poema habla del duelo en el exilio, del traslado de todo lo llorado; el poeta no sólo hace una inserción del yiddish y del hebreo, por ejemplo en la última línea: “Ziw, jenes Licht” (Obras completas 300$)^{11}$ sino que también presenta, como lo muestra Nitzan Leibovic, una intertextualidad con un poema en yiddish de Moshe Leyb-Halpernde de 1919 que fue adoptado en los guetos. En este sentido, el poema es también un espacio de conmemoración de aquel mundo judeo-alemán.

En El monolingüismo del otro, Derrida enuncia una ley a partir de la negación de dos presupuestos corrientes sobre las lenguas: 1) Que la lengua, principalmente la lengua materna, es una propiedad natural y que ella asegura la identidad y la pertenencia a una comunidad, 2) Que la lengua es homogénea y común a sus hablantes, que existe algo como la "unidentidad" de la lengua. Estas dos preposiciones se resumen en una frase paradójica: "Sí, no tengo más que una lengua; ahora bien, no es la mía” (38).

Una de las mayores exigencias de hablar una lengua es obliterar su dimensión institucional: puesto que la lengua no es un bien natural, su apropiación requiere desarrollar e inclusive redoblar la violencia. Como ya hemos mencionado antes, Derrida sostiene que nunca hay apropiación absoluta de la lengua a pesar de que la exigencia para todo hablante parecería ser apropiarse sus normas y obliterar la dimensión institucional, es decir, naturalizar la lengua. Esto tiene una implicación según Derrida: "Dado que no hay propiedad natural de la lengua, ésta no da lugar más que a la furia apropiadora, a los celos sin apropiación" (38). La posibilidad de deconstruir la relación del singular a la lengua depende de "un proceso no natural de construcciones político-fantasmáticas" (38). Y son estas construcciones justamente las que dan lugar a la furia apropiadora que cuestiona el idioma.

Derrida describe el idioma en tanto deseo, una pulsión a partir del desarraigo, un movimiento hacia la anamnesis que es también destructor de las normas del "hablar bien-escribir bien", pero, a su vez, el idioma responde en Derrida a una exigencia ética, la de "inventar" en la lengua para dirigirse al otro, ahí donde su heterología promete una lengua por venir:

10 NAH, IM AORTENBOGEN,/ im Hellblut:/das Hellwort.//Mutter Rahel/weint nicht mehr/Rübergetragen/alles Geweinte.//Still, in den Kranzarterien,/unumschnürt:/Ziw, jenes Licht.

CERCA, EN EL ARCO DE LA AORTA/, en la sangre clara:/ la palabra clara.//Madre Raquel/ya no llora./Trasladado aquí/todo lo llorado.//Silente, en las arterias coronarias,/desatada:/Ziw, aquella luz. [traducción de Reina Palazón].

11 Según Felstiner, Celan toma la palabra "Ziw" de la lectura de un libro de G. Scholem, donde éste último se refería con Ziw a un esplendor luminoso sobrenatural en relación a la Shejina (ver Fesltiner, op.cit. 330). Felstiner subraya que Ziw aparece en una plegaria matutina y en un canto de la noche del Sabbat, Yedid Nefesh, que Celan puede que recordara (Ibíd. 434). 
[...]Inventa por lo tanto en tu lengua si puedes o quieres entender la mía, inventa si puedes o quieres hacer entender mi lengua como la tuya, allí donde el acontecimiento de su prosodia no sucede más que una vez en su hogar, allí mismo donde su "en su hogar" molesta a los cohabitantes, los conciudadanos, los compatriotas? ¡Compatriotas de todos los países, poetas-traductores, rebelaos contra el patriotismo! (81-2).

Aquí aparece el idioma como una invitación, sobre todo a poetas y traductores, una invitación a crear en la lengua para entender al otro, ahí donde la lengua nunca está "en su hogar" ni uno está en casa en su lengua, ahí donde el idioma molesta las ideologías nacionalistas que siempre comprometen una apropiación de la lengua. Derrida habla de inventar una preprimera lengua ("avant première langue") que no es una lengua originaria o en el origen sino una lengua únicamente de llegada o porvenir, cuya posibilidad imposible se signa en un evento que sobrepasa su condición de posibilidad. Esto se explica porque la lengua no es, ella está prometida. El idioma apela a la traducción de una lengua que aún no existe y cuyo origen está perdido, es por ello que la lengua es según Derrida "más de una”. Puesto que esta pre-primera lengua no es de origen sino que el origen de la lengua es un "más de uno", [plus d’un], la dimensión colonialista de la cultura intentará reconstruir su genealogía. Pero esta exigencia de apropiación se ve confrontada por el deseo de inventar una lengua o prometer una lengua en un horizonte mesiánico. Aquí encontramos temas presentes en el pensamiento político de Derrida como el mesianismo, la espectralidad y el evento. Es por ello también que el poeta no representa aquí una figura nacional sino un guardián de la memoria y un testigo que da lugar a la palabra del otro, ahí donde la singularidad de cada poema y de su lectura exigen una decisión política:

[El idioma] se erige incluso como deseo de reconstituir, de restaurar, pero en realidad de inventar una primera lengua que sería más bien una preprimera lengua destinada a traducir esta memoria. Pero a traducir la memoria de lo que precisamente no tuvo lugar, de lo que, tras haber sido (la) interdicción, debió no obstante dejar una huella, un espectro, el cuerpo fantasmal, el miembro fantasma -sensible, doloroso, pero apenas legible- de huellas, de marcas, de cicatrices (102).

Y esas marcas, cicatrices, guiarán hacia una relación entre idioma y duelo. Es así que Derrida evoca a Celan hacia el final de El Monolinguismo del otro, para hablar de la "apertura heterológica" que le permite dirigirse al otro: "También se puede traducirlo en el idioma de Celan, ese poeta-traductor que, pese a escribir en la lengua del otro y del holocausto, e inscribir a Babel en el cuerpo mismo de cada poema, sin embargo reivindicó expresamente, firmó y selló el monolingüismo poético de su obra” (111). 


\title{
2. Duelo e idiomaticidad
}

\author{
Una hora de rosas a veces se armoniza. \\ Extinguiéndose. Una. Siempre una... \\ ¿Qué sería, madre: crecimiento o herida - \\ si yo también me hundiera en las nieves de Ucrania?
}

Paul Celan

Hemos decidido abordar El monolingüismo del otro antes que Schibboleth para Paul Celan, a pesar de que ésta última se publica once años antes, porque nos parece importante entender la relación entre el monolingüismo y la pulsión del idioma para abordar la cuestión de la singularidad que, en Schibboleth se adscribe al problema entre la generalidad de la fecha y la singularidad del evento. La singularidad de una fecha, al igual que toda firma, depende de su iteración: "Como el calendario, el reloj nombra el retorno de lo otro, de lo enteramente otro en lo mismo" (76). Y, sin embargo, a pesar de la generalidad de una fecha, ésta habla de un evento único, singular. Derrida desarrolla en Schibboleth la relación entre la fecha, la firma y el idioma: "Dondequiera que una firma viene a encentrar el idioma para dejar en una lengua una huella, la memoria de una incisión a la vez única e iterable, críptica y legible, se da la fecha" (81). Aquí Derrida retoma la idiomaticidad como una huella o una firma en la lengua pero también en su dimensión corpórea, como incisión o memoria de una incisión que abre a una paradoja de la lectura, pues si bien es críptica, debe ser legible.

Derrida abre Schibboleth con la circuncisión como esa "única vez" que marca el cuerpo -que ya había tratado con anterioridad en Circunfesión- en esta ocasión, Derrida recurrirá a la poesía de Celan para hablar de la circuncisión de la palabra a partir en la última estrofa del poema "Einem, der vor der Tür stand" en el que Celan apostrofa al Rabí Löw y le dice en modo imperativo "circuncídale la palabra" (beschneide das Wort). Inclusive pareciera que el mismo nombre del Rabí Löw -aquel a quien se le atribuye la invención del Golem- se circuncida en el último verso: "Cierra también la puerta de la tarde, Rabí./Abre de golpe la puerta de la mañana, Ra"12 (Celan 172).

Derrida recuerda que la circuncisión es también un rito en el que se da al niño el nombre propio; de alguna manera, es un rito que significa la entrada legítima a una comunidad con una marca carnal y un nombre: es el reconocimiento de un singular. Derrida habla asimismo de un quehacer del poeta o del poeta como judío

12 Derrida sugiere que el nombre del Rabí cortado en dos puede invocar igualmente al dios egipcio del sol "Ra" en la apertura de la puerta de la mañana que, a su vez, recuerda que la circuncisión también era practicada por los egipcios y otros pueblos. 
al circuncidar la palabra - Derrida recuerda el epígrafe de Marina Tsvetiaieva en el poema "Und mit dem Buch aus Tarussa"(Con el libro de Tarussa): “Todos los poetas son judíos”, todos los poetas de alguna manera circuncidan la palabra, es decir, la ofrecen al otro: "[...] esta palabra que hay pues que dar, y dar una vez circuncidada, entendámosla como una palabra abierta” (Schibboleth 95), y Derrida especifica: "Abierta ante todo como una puerta, abierta al extranjero, al prójimo, al huésped o a cualquiera. A cualquiera, sin duda, en la figura del porvenir absoluto" (Ibíd.). Este último párrafo relaciona la idiomaticidad y el mesianismo, el idioma como una palabra circuncidada para el otro que inaugura un tiempo bajo la forma mesiánica de un porvenir absoluto.

Schibboleth es una lectura de Celan a partir de las fechas que el poema guarda, recuerda, y conmemora. Derrida cita la afirmación de Celan en El Meridiano a propósito de una pregunta: “¿Se puede decir tal vez que en cada poema queda grabado su '20 de enero'13?" (505). A lo que responde: “Aber das Gedicht spricht ja! Es bleibt seiner Daten eingedenk, aber - es spricht. Gewiss, es spricht immer nur in seiner eigenen, allereigensten Sache." (“¡Pero el poema habla! Recuerda sus fechas, habla. Por supuesto habla siempre en nombre de su propia causa, en su más propia causa") (Ibíd.). Celan inventa una palabra para referirse a la singularidad de la que habla cada fecha: "allereigensten": el poema habla de "lo más propio de todo", de lo más propio entre todo. Y, sin embargo, si a Derrida le interesa la fecha en la poesía de Celan es por esa estructura que relaciona la generalidad con lo singular, con lo más propio de todo; Derrida piensa la fecha en cierto sentido como un signo, que depende de su iteración para significar. Derrida describe también la fecha como metonimia: "La metonimia de la fecha [...] designa la parte de un acontecimiento o de una secuencia de acontecimientos a fin de recordar el todo"(Schibboleth 41). En este sentido, Derrida lee el poema "Todo en uno" ["In Eins"] que inicia con un "Trece de febrero" que concentra en una misma fecha y en cuatro lenguas, eventos como la victoria electoral del Frente Popular en España que en el poema se inscribe con un schibboleth ${ }^{14}$ en español: "No pasarán”, las manifestaciones en París, el peuple de Paris, el crucero Aurora, cuya tripulación se unió a la revolución de febrero (de 1917) antes de dar inicio a la revolución de octubre. La fecha es aquí una manera de firmar desde el idioma y, a su vez, es un schibboleth, es decir, una contraseña. Derrida recuerda la anotación de Peter Szondi según la cual los poemas de Celan aparecen siempre fechados en el manuscrito en limpio pero no en la publicación. En algunos casos, como la lectura que Szondi hace del poema "Edén" (Szondi 105-114) fechado el 22/23 de diciembre de 1967, que coincidió con un viaje a Berlín que realizaron juntos, la fecha permite

13 Es importante mencionar que el 20 de enero refiere al Lenz de Büchner pero también al día en que tuvo lugar en 1942 la conferencia de Wansee en donde se decide la solución final.

14 Recordemos que Schibboleth refiere al pasaje bíblico de la guerra entre los Efraimitas y los de Galaad, que funcionaba como una palabra clave para pasar [un mot de passe] puesto que los Efraimitas no podían pronunciar "Schi" (Jueces 12: 4-6). 
ofrecer una interpretación sobre algunos eventos encriptados como el mismo título del poema "Eden" que refiere al hotel Eden que también había sido el lugar en donde Luxemburg y Liebknecht -sobre quienes Celan leía un libro que Szondi le prestópasaron sus últimas horas antes de ser asesinados, y frente al cual pasan durante su estancia en Berlín. No obstante, dice Derrida, si bien estos indicios son invaluables no dejan de ser suplementos de inteligibilidad de los cuales el poema puede prescindir, pues el poema también trabaja como cripta ${ }^{15}$, es decir, la fecha opera entre el secreto y la conmemoración.

Derrida predica de la fecha de distintas maneras: "Fechar viene a ser lo mismo que firmar" (29); "La fecha es un futuro anterior" (47); "La fecha es un testigo" (58). Todos estos predicados ahondan en la cuestión de la singularidad. En cuanto a la fecha como testigo, Derrida cita un poema de Aschenglorie: "Niemand/zeugtfür den/ Zeugen" "Nadie/testimonia por el/testigo" (Obras completas 235) ${ }^{16}$ al cual le dedicará una lectura e inclusive un intento de traducción en "Poétique et politique du témoignage". Derrida sostiene que la fecha opera como un testigo sin por ello saber lo que testifica; es decir, como un schibboleth, pero a su vez, para que haya un testimonio responsable, el poema debe darle la palabra al testigo para que pueda hablar desde la singularidad irreductible de su historia. En Schibboleth Derrida escribe: "Lo encriptado, lo fechado de la fecha se borra, la fecha se marca desmarcándose, y todas las pérdidas, todos los seres que lloramos en ese duelo, todos los dolores se recogen en el poema en una fecha cuya borradura no espera la borradura"(64).

En Carneros: entre dos infinitos, el poema, que publica en 2003 en memoria de Gadamer, Derrida habla de la fecha melancólica en relación a la muerte del amigo, que recuerda el título de otra obra publicada el mismo año: Cada única vez el fin del mundo [Chaque fois unique la fin du monde] en la que Derrida evoca la memoria de sus amigos muertos. Cada muerte como el fin del mundo, como una única vez singular e irremplazable. Esta única vez exige que el lenguaje diga la singularidad de la pérdida, es por ello que la muerte del amigo convoca al idioma para decir por un lado, la melancolía que se instaura en toda relación como un futuro anterior, pues uno de los dos, dirá Derrida, morirá antes que el otro. Por otra parte, el idioma dice esa condición del duelo que Derrida retoma de Freud, aunque contraria a la idea de superación en un trabajo de duelo: la de portar al otro en sí, la de interiorizar el diálogo interrumpido por la muerte e ininterrumpido en la interioridad del sobreviviente.

15 Derrida subraya que schibboleth no significa realmente río, espiga o ramilla de olivo según su lengua de origen... Lo que significa es: hay schibboleth, hay cripta.

16 Derrida cita la traducción de Jean-Pierre Lefèbvre: "Personne ne témoigne pour le témoin" y la traducción de André du Bouchet "Nul ne témoigne pour le témoin". 
Derrida cita en Carneros la última frase de un poema ${ }^{17}$ incluido en el libro Atemwende (Cambio de aliento): "Die Welt ist fort, ich muss dich tragen" que Palazón traduce como "El mundo se ha ido, yo tengo que llevarte" (Obras completas 251), y que Derrida deja sin traducir en la edición en francés, como si el diálogo con Gadamer sobre Celan prosiguiera en alemán. Sobre esta frase y su idiomaticidad regresará una y otra vez Derrida en Carneros, no sólo para mostrar la responsabilidad del sobreviviente, ahí donde el mundo se ha ido, inclusive ahí donde el poema nos es confiado como único sobreviviente, sino también para ahondar en el concepto de "mundo" y del verbo llevar (tragen) en este poema. Por un lado, llevar (tragen) dice Derrida, es el lenguaje del nacimiento, de la madre que porta, lleva a su hijo, por otro lado, es el verbo de los espectros o de la experiencia del duelo que consiste en llevar al otro dentro de sí, introyectarlo, portar al otro y su mundo. Estos dos sentidos también abren para Derrida una reflexión sobre el sentido de "mundo" y en las últimas páginas de Carneros menciona sin desarrollar una crítica a la noción de ser-en-el-mundo de Heidegger que retoma también en el Seminario La Bestia y el soberano volumen II ${ }^{18}$, sobre todo en relación a los conceptos de weltlos (sin mundo) que se atribuye por ejemplo a la piedra, weltarm (pobre de mundo) que Heidegger indexa al animal y que Derrida criticará largamente en El animal que luego estoy si(gu)iendo y, weltbinden, el configurador de mundo que sería el hombre. Derrida sugiere que en este poema de Celan, el "mundo" no responde a ninguna de estas tres categorías. La frase de Celan habla de aquellos que no tienen mundo o que se quedaron pobres de mundo, como diría Celan en el discurso de Bremen: "herido de realidad y buscando realidad", ahí donde cada uno tiene la responsabilidad de guardar la palabra del testigo, de asegurarle un lugar aún cuando el mundo haya desaparecido.

Para que el testigo pueda hablar en su nombre, todo testimonio exige una relación inventiva con la lengua. La poética que funda el poema, en su acontecer mismo, revela su dimensión intraducible. El poema es intraducible porque da testimonio de eventos en la lengua, en este sentido, sólo la lengua alemana puede dar testimonio de la herida idiomática de un poema de Celan. Sin embargo, pensar en el testimonio como dimensión política de lo poético no puede simplificarse en una generalización sobre la relación del poema con la lengua, sino que exige leer, en una lectura cada vez única, en una interpretación inventiva, la singularidad de cada poema. Esta responsabilidad de la lectura es intransferible, la responsabilidad del idioma no le corresponde únicamente al poeta, sino que cada uno debe ser capaz de prometer una lengua al porvenir y de prometerla al otro.

La dimensión de alteridad en el testimonio es la que justamente relaciona al poema con el duelo. El poema habla al otro, da testimonio del otro o da testimonio del tiempo del otro en sí como origen de la temporalidad. Dicha alteridad en el pre-

17 El poema inicia con la frase GROSSE, GLÜHENDE WÖLBUNG, que Palazón traduce "Vasta bóveda encendida”.

18 Ver por ejemplo la primera y la cuarta sesión del seminario (Derrida 2011). 
sente que había sido el núcleo de la deconstrucción de la metafísica aparece ahora relacionada a la cuestión del duelo: el tiempo del otro en sí es el del sobreviviente, aquel que guarda la memoria del amigo muerto, que guarda su voz. Derrida para hablar de esta alteridad del yo en el duelo nos remite al poema "La Esclusa" ("Die Schleuse") recopilado en La rosa de nadie (Die Niemandsrose). Celan escribe este poema eminentemente judío en 1960 a la sazón de un difícil encuentro con Buber en París -ya que el filósofo de las historias hasídicas no comprendió la pregunta de Celan sobre la dificultad de escribir en alemán después de lo ocurrido ${ }^{19}$ - poema que también lleva una dedicatoria a Nelly Sachs: "hermana" ${ }^{20}$. Derrida muestra no sólo que éste es un poema de duelo sino la marca singular de su idiomaticidad en dos palabras intraducibles relacionadas al duelo judío: kaddish que significa santo en arameo y es el nombre de una oración para los muertos e yiskor que significa "Él recordará" y designa un rito conmemorativo.

\section{La Esclusa}

Sobre todo este duelo

tuyo: ningún

otro cielo.

Ante una boca,

para la que era una palabra entre mil, perdí una palabra, que me había quedado:

hermana.

Ante

múltiples dioses

perdí una palabra que me buscaba:

Caadish.

A través de

la esclusa tuve que pasar

para salvar la palabra de vuelta,

hacia fuera y más allá de la corriente salada:

Yiskor.

\author{
Die Schleuse \\ Über aller dieser deiner \\ Trauer: kein \\ zweiter Himmel. \\ An einem Mund, \\ dem es ein Tausendwort war, \\ verlor- \\ verlor ich ein Wort, \\ das mir verblieben war: \\ Schwester.
}

An

die Vielgötterei

verlor ich ein Wort, das mich suchte:

Kaddisch.

Durch

die Schleuse musst ich, das Wort in die Salzflut zurückund hinaus-und hinüberzuretten:

Jiskor (Obras completas 160). 
En Schibboleth, Derrida señala que este poema se dirige a un tú, a su duelo "[...] para decirte que lo que está perdido, y sin resto, es la palabra, una palabra que actúa, como un schibboleth, en lo más íntimo." Si es necesario llevar al poema, aún cuando el mundo ha partido, cuando un mundo ha sido exterminado, es necesario guardar en sí al poema como un lugar de memoria ${ }^{21}$, puesto que el poema recuerda a los muertos en la marca singular de su idiomaticidad, que busca también las palabras, dos palabras que no pueden traducirse en alemán y de las que ningún judío requiere de traducción.

Este poema también nos hace pensar en el duelo por las palabras que se pierden y se buscan o mejor dicho, el esfuerzo por salvar la palabra. Recuerda lo que Celan dice en el Discurso con motivo del premio de la ciudad de Bremen en 1958, ese primer discurso importante sobre la poesía, en el que Celan habla a un auditorio alemán y dice a propósito de la lengua (nunca menciona que se trata de la lengua alemana pero queda sobrentendido):

Accesible, próxima y no perdida permaneció, en medio de todas las pérdidas, sólo una cosa: la lengua. Sí, la lengua no se perdió a pesar de todo. Pero tuvo que pasar entonces a través de la propia falta de respuesta, a través de un terrible enmudecimiento, pasar a través de las múltiples tinieblas del discurso mortífero. Pasó a través y no tuvo palabras para lo que sucedió; pero pasó a través de lo sucedido. Pasó a través y pudo volver a la luz del día, 'enriquecida' por todo ello (Obras completas 497).

El idioma justamente permite que la lengua pase a través, atraviese el discurso mortífero, la palabra sobreviviente de ese mundo de "aquellas historias hasídicas de Martín Buber nos ha vuelto a contar en alemán” (Ibíd.), en un momento en el que su natal Bukovina ha desaparecido de los mapas; así, esta palabra que tiene que pasar a través, ¿de una esclusa?, atravesar la lengua para dirigirse a alguien, a un tú asequible; puede pensarse también en el sentido de la contra-palabra de la que hablará Celan en El Meridiano, que opera como una contra-violencia ante la falta de respuesta y el enmudecimiento. Esta dimensión política y revolucionaria del idioma ya estaba de alguna manera cifrada en la fecha como testimonio, también en el idioma, que si bien Derrida describe como una pulsión, cuestiona la naturalización de la lengua y por ende toda postura colonialista de la cultura.

21 Sobre la memoria en la poesía de Celan, me permito remitir al lector a mi artículo "Memoria y Voces. Paul Celan" (Jerade 2006). 


\section{La contra-palabra}

Poesía: eso puede significar un cambio de aliento

Paul Celan, El Meridiano

En la octava sesión del seminario La bestia y el soberano, Derrida se detiene expresamente en el grito de Lucile cerca del cadalso: “¡Viva el Rey!”, un grito suicida en plena Revolución Francesa, que Celan, en la lectura que realiza de La muerte de Dantón en ocasión de la entrega del premio Georg Büchner, nombra una contra-palabra (Gegenwort):

Después de todas las palabras pronunciadas en la tribuna (es el cadalso) ¡qué palabra!

Es la contra-palabra [Es ist das Gegenwort], es la palabra que rompe el "hilo", la palabra que ya no es la reverencia hecha "a los mirones y a los figurones de la historia", es un acto de libertad. Es un paso (Obras completas 501).

Es importante tener en mente que el seminario del cual forma parte esta lectura de Celan está guiado por la cuestión de la soberanía. Derrida subraya que el “¡Viva el Rey! de Lucile no es un saludo a la monarquía sino un saludo a la majestad de la poesía. La cuestión reside ante todo en cómo esta contra-palabra de aquella que es, dice Celan, "ciega al arte", es "un acto de libertad", "un paso". Derrida, sin pretender hacer un análisis hermenéutico del texto de Celan sin arrojar luz sino sombra ${ }^{22}$ muestra tres dimensiones de esta contra-palabra que rompe el hilo y sustrae al “iViva el Rey!” de su código político (Derrida, La bestia 272). Celan escribe en El Meridiano:

Pero aquí $[\ldots]$ no se trata de un homenaje a la monarquía, ni a las cosas de antaño que se trataría de conservar. Aquí se rinde homenaje a una majestad del presente que da testimonio de la presencia de lo humano, la majestad del absurdo. Y eso, señoras y señores, eso no se deja nombrar de una vez por todas, pero yo creo que es... la poesía (501).

Me gustaría analizar tres dimensiones de las cuales testimonia la poesía según Celan y, que serán el eje de la lectura que Derrida hará de El Meridiano a partir de esta sobrepuja hiperbólica de la soberanía o de la majestad: 1) la majestad del absurdo, 2) la majestad del presente y 3 ) el testimonio.

Primeramente, la contra-palabra está relacionada a la inversión del sentido que hace a la poesía "aún más majestuosa" "tanto más majestuosa" que la majestad del rey que contradice el concepto de soberanía. Esa hipermajestad de la poesía "[...] más

22 "Habla-/ Pero no separes el No del Sí./ Y da a tu decir sentido:/ dale sombra". "Paul Celan, Habla también tú" (Obras completas 108). 
allá o fuera de la majestad del rey, del soberano o del monarca, esa majestad suprema del absurdo, como majestad de la Dichtung..." (Derrida, La bestia 273) tiene una dinámica, una potencia que está por encima de la soberanía y que según Derrida se resume en el valor de la presencia o del presente [Gegenwart] que, como veremos, es una presencia habitada por el otro, es la presencia del testigo atravesada por la espectralidad de la palabra del otro.

En cuanto al absurdo, además de referirse a "aquello que se sitúa más allá del sentido, de la idea, del tema e incluso de los tropos de la retórica, de toda la lógica y de toda la retórica, a los que uno cree que debe plegarse una poética" (272), éste da testimonio, como Derrida lo expone en la décima sesión, de una salida fuera de lo humano que sería, según explica El Meridiano, lo propio del arte: "una especie de marioneta, un ser de cinco pies yámbicos" (Celan 499), esos seres a-humanos pero sobre todo ominosos a los que Celan nombra desde el principio de su alocución: las marionetas, los autómatas, la cabeza de Medusa, la figura del mono. Esta condición de lo ominoso [unheimlich] - que Derrida analiza en el seminario en referencia a la Introducción a la metafísica de Heidegger, ahí donde según Derrida, el filósofo alemán abandona a Parménides y retoma a Sófocles subrayando el carácter demoniáco, deinón del hombre, que Heidegger traduce por unheimlich, ahí donde lo propio del hombre sería la expropiación de todas las identificaciones y el superlativo que marca que el hombre es el más unheimlich, coronaría al Dasein de una cierta soberanía. Derrida retoma particularmente estos dos pares: soberanía y superlativamente unheimlich, extranjero y extrañeza.

Lo ominoso puede atribuirse al idioma como lo terriblemente inquietante de la extrañeza en lo propio, en lo íntimo. El arte sería para Büchner, según Celan: "etwas Unheimliches", el arte se encuentra en esa salida fuera de lo humano donde aparece la cabeza de Medusa "para captar lo natural como natural por medio del arte”. Los autómatas, las marionetas aquellos que están en el arte como en su casa, también están entre la vida y la muerte. La marioneta es vista como fetiche, como simulacro o prótesis, dibuja esa línea entre la vida y la muerte, el arte y la naturaleza. Derrida lo relaciona también con el aliento como primer y último signo de vida, que es una de las definiciones que Celan da de la poesía en El Meridiano: "Dichtung: das kann eine Atemwende bedeuten" (Poesía: eso puede significar un cambio de aliento) (504).

En cuanto a la majestad del presente, Derrida retoma, por un lado, el presente vivo de Husserl (lebendige Gegenwart): no una esencia o substancia de la vida sino el atributo de lo viviente que califica al presente, lo viviente sin ser, en la majestad del presente. Por otro lado, Celan habla del presente e inclusive de la presencia del poema como palabra de un solo [Sprache eines Einzelnen]: "El poema sería pues -de una forma todavía más señalada- palabra de uno solo, que ha adquirido forma y, en su esencia más íntima, presente y presencia" (506). Esta última frase expone ya la relación entre idiomaticidad y singularidad; Celan precisa algo esencial a la estructura 
de este presente del poema: en su aquí-ahora debe dejar hablar al otro, al tiempo del otro. Aquí Derrida complica la frase en francés con una ambigüedad del posesivo: "Debe ofrecerle su tiempo" [À l'autre, il doit laisser ou donner son temps]. En este equívoco gramatical se cifra la lectura de Derrida, pues la majestad del presente está atravesada por el otro, por el tiempo del otro, pero también por el testimonio que es un ofrecer el tiempo al otro.

Derrida escribe que el poema es una palabra de "más de uno", que recuerda la ley del idioma como "más de uno en la lengua" pero sería también la ley del testimonio, el tiempo del otro que según Derrida sería una contrafirma de la palabra del testigo cifrada en lo intraducible. Por un lado, el poema es la palabra de un solo, esta soledad según Lacoue-Labarthe es la singularidad del poema; por otro lado, dejar hablar al otro es, según Derrida, la condición del evento. En este sentido, la soledad de la presencia está atravesada por el otro, se torna hacia el otro en el secreto del encuentro [Geheimnis der Begegnung] -Hacia el final de El Meridiano, Celan menciona diez veces la palabra "encuentro": El secreto del encuentro es lo que hace al poema, tanto en su factura como en su firma.

Hay, en el fondo, dos encuentros: el encuentro con el poema y el encuentro con el otro, lo que hace que el poema nunca se presente. Esta alteridad en el tiempo permite que el poema sea un don al otro o el don del otro que invierte el aliento [Atemwende]. El poema le habla al otro y habla con el otro, habla en una fecha de una fecha. Y en soledad, pues da testimonio del tiempo del otro en sí como origen de la temporalidad. Esta alteridad en el presente que había sido el núcleo argumental de la deconstrucción de la metafísica, vuelve a la cuestión del duelo: el tiempo del otro en sí es el del sobreviviente, aquel que guarda la memoria y la voz del amigo muerto sin poder integrarlo en un trabajo de duelo. Derrida vuelve al " 20 de enero" de Lenz y al de Celan para retomar el testimonio del poema, de su aquí y ahora, en esa memoria de las fechas que es el poema y que en su iteración puede también operar como una contra-violencia ante el olvido.

No obstante, hacia el final de la décima sesión de La bestia y el soberano I, Derrida subraya otra figura, ya no la contra-palabra del “¡Viva el Rey!” de Lucile, sino el de Büchner como corte de aliento. Celan escribe:

Lenz -es decir Büchner-fue, aquí, un paso más allá de Lucile. Su “iViva el Rey!” ya no son unas palabras [Sein "Es lebe der König" ist kein Wort mehr], es una terrible parada en seco de la palabra [Es ist ein furchtbares Verstummen], la parada de alguien a quien -también el nuestro- se le cortan el aliento y la palabra [es verschlägt ihm -und auch uns- den Atem und das Wort] (Obras completas 505).

Habría que preguntarse cómo el corte de aliento, el silencio puede responder a la violencia de la autoridad discursiva y, a su vez, dejar un lugar para que la alteridad pueda hablar y dar el testimonio idiomático de ese encuentro. En "Poétique et politique du témoignage" Derrida escribe: 
Le témoignage n’est pas de part en part et nécessairement discursif. Il est parfois silencieux. Il doit engager quelque chose du corps qui n’a pas droit à la parole. On ne doit donc pas dire, ou croire, que le témoignage est tout entier d'ordre discursif, de part en part langagier $(528)^{23}$.

Sin embargo, justamente aquello que no tiene derecho a la palabra puede asimilarse a la peor violencia; en cierto sentido, la soberanía significa, entre otras cosas, gestionar esta imposición. Y, no obstante, darle palabra a algo del cuerpo es abrirse a la escucha de la más grande singularidad, darle derecho a una palabra propia. La única manera de responder a la violencia es quizás una contra-palabra que sea capaz de invertir el aliento y parar en seco el discurso de la soberanía para dejar hablar al otro.

\section{Conclusión}

El hecho de que el singular pueda firmar en la lengua y que una poética sea siempre un evento singular, algo que adviene a la lengua, implica una dimensión política por tres factores según Derrida: 1) porque abre a la posibilidad del testimonio que es siempre singular 2) porque concede alteridad tanto a la lengua como al tiempo, al presente vivo; pero este presente atravesado por la alteridad no puede pensarse desde un tiempo universal y homogéneo sino únicamente desde la singularidad 3) porque en su intraducibilidad el idioma revierte toda política de la homogeneidad de la comunicación, haciendo que entre la lengua de partida y la lengua de llegada ocurra algo completamente único.

El idioma como la posibilidad del singular de marcar la lengua para ofrecerla al otro, en el evento de su creación poética, nos encamina a pensar en una política de la singularidad, tanto por la agencia que tiene el singular sobre la lengua y por ende, la responsabilidad de abrirla y prometerla al otro, como por el testimonio, en un doble sentido: el de dejar hablar al otro y el de hacer que la lengua dé testimonio de la singularidad del encuentro.

Si toda política nacionalista conlleva de alguna manera la exigencia de apropiación de la lengua y de sus normas, el idioma contrarresta toda política de la hegemonía lingüística. El discurso soberano se sostiene, entre otras cosas, en la idea de la "unidentidad de la lengua" y en la conmemoración de ciertas fechas y el olvido de otras. En este sentido, Derrida avanza desde Schiboleth una política de la singularidad que depende del evento de una poética.

23 "El testimonio no es de parte a parte necesariamente discursivo. A veces es silencioso. Éste debe comprometer algo del cuerpo que no tiene derecho a la palabra. No debemos entonces decir, o creer, que el testimonio es enteramente de orden discursivo, de parte a parte lingüístico" (La traducción es nuestra). 


\section{Referencias}

Bennington, Geoffrey. “Double Tonguing: Derrida’s Monolingualism”, Tympanum 4, (2000). http://www.usc.edu/dept/comp-lit/tympanum/4/bennington.html. Fecha de ingreso: 23 de junio de 2013. Sitio web.

Bennington, Geoffrey y Jacques Derrida. Jacques Derrida. Trad. Ma Luisa Rodríguez Tapia, Madrid: Cátedra, 1994. Medio impreso.

Bollack, Jean. Poesía contra poesía. Celan y la literatura. Trad. Arnau Pons. Madrid: Trotta, 2005. Medio impreso.

Celan, Paul. Obras Completas. Trad. José Luis Reina Palazón, Madrid: Trotta, 1999. Medio impreso.

Crépon, Marc. Les promesses du langage, Paris: Vrin, 2001. Medio impreso.

---. Langues sans demeure, Paris: Galilée. 2005. Medio impreso.

---. “Traduire, témoigner, survivre”. Rue Descartes 52 (2006). 27-38. Medio impreso. Derrida, Jacques. La escritura y la diferencia. Trad. Patricio Peñalver. Madrid: Anthropos, 1989. Medio impreso.

---. El monolingüismo del otro. Trad. Horacio Pons. Buenos Aires: Manantial, 1997. Medio impreso.

---. La verdad en pintura. Trad. María Cecilia González y Dardo Scavino, Paidós: Barcelona, 2001. Medio impreso.

---. Schibboleth. Para Paul Celan, traducción de Jorge Perez de Tudela, Madrid: Arena, 2002. Medio impreso.

---. "La lengua no pertenece". Trad. Ricardo Ibarlucía. Diario de Poesía 58 (primavera 2001). http://www.egs.edu/faculty/jacques-derrida/articles/la-lengua-nopertenece. Fecha de ingreso: 23 de junio de 2013. Sitio web.

---. "Poétique et politique du témoignage". Cahier de L'Herne Jacques Derrida, MarieLouis Mallet et Ginette Michaud (Eds.), Paris: L'Herne, 2004. Medio impreso.

---. Cada única vez el fin del mundo. Trad. Manuel Arránz. Valencia: Pre-Textos, 2005. Medio impreso.

---. El animal que luego estoy si (gu)iendo. Trad. Cristina de Peretti y Cristina Rodriguez Marciel. Madrid: Trotta, 2008. Medio impreso.

---. Carneros: entre dos infinitos, el poema. Trad. Irene Agoff, Buenos Aires: Amorrortu, 2009. Medio impreso.

---. La bestia y el soberano, volumen I. Trad. Cristina de Peretti y Dalmiro Rocha, Buenos Aires: Manantial, 2010. Medio impreso.

---. La bestia y el soberano, volumen II. Trad. Cristina de Peretti y Dalmiro Rocha, Buenos Aires: Manantial, 2011. Medio impreso.

Felstiner, John. Paul Celan. Poeta, superviviente, judío. Trad. Carlos Martín y Carmen González, Madrid: Trotta, 2002. Medio impreso.

Jerade, Miriam. “Memoria y voces. Paul Celan”. Acta Poética 23, 2 (otoño 2006). 151166. Medio impreso. 
Kafka, Franz. Gesammelte Werke. Max Brod (Ed.). New York: Schocken, 1953. Medio impreso.

Lacoue-Labarthe, Philippe. La poésie comme expérience. Paris: Christian Bourgois, 1986. Medio impreso.

Levine, Michael. "Spectral Gatherings: Derrida, Celan and the Covenant of the Word" Diacritics, "Derrida and Democracy" 38. 1-2 (Primavera-Verano 2008). 64-91. Medio impreso.

Szondi, Peter. Estudios Sobre Celan. Trad. Arnau Pons. Madrid: Trotta, 2005. Medio impreso.

Recibido: 24 octubre 2013

Aceptado: 05 septiembre 2014 